\title{
Parental age and birth order in Chinese children with congenital heart disease
}

\author{
JOHN S H TAY, WILLIAM C L YIP, AND R JOSEPH \\ From the Department of Paediatrics, National University of Singapore, Singapore.
}

SUMmARY Parental age and birth order were studied in 100 Chinese children with congenital heart disease (proven by cardiac catheterisation) and in 100 controls. A higher incidence of congenital heart disease was present in the children with higher birth orders. No relationship was found between the incidence and the paternal or maternal ages. Using the method of multiple regression analysis this birth order effect was significant $(\mathrm{p}<0 \cdot 01)$ and independent of parental age. This finding provides indirect evidence of environmental influence in the causation of congenital heart disease, which is known to be inherited in a multifactorial manner. Family planning to limit the size of the family may possibly contribute to the reduction of the incidence of congenital heart disease.

Parental age and birth order effects have been demonstrated in a number of genetic diseases and congenital malformations. Certain chromosomal disorders such as trisomy 21 (Down's syndrome), trisomy 13 (Patau's syndrome), trisomy 18 (Edwards's syndrome), and Klinefelter's syndrome have been shown to be related to maternal age. ${ }^{1}$ Some autosomal dominant disorders such as Apert's syndrome, Marfan's syndrome, and achondroplasia are related to paternal age. ${ }^{2} \mathrm{~A}$ number of congenital malformations have been shown to be related to birth order. ${ }^{3}$ Congenital dislocation of the hip and congenital pyloric stenosis occur more frequently in first born children, and anencephaly and spina bifida are more common among first born children as well as in high birth orders. ${ }^{4}$

The rationale of studying parental age and birth order effects is that the results of such studies may shed some light on pathogenesis. The presence of a parental age or birth order effect is presumptive evidence of an environmental influence in the causation of the disease. ${ }^{1}$ This kind of information may also be of help in genetic counselling.

The purpose of this study was to investigate the parental age and birth order effects in Chinese children with congenital heart disease.

\section{Materials and methods}

The material consisted of 100 consecutive Chinese children with congenital heart disease proven by

Raceived for publication 9 April 1982. cardiac catheterisation. The parental ages (at the birth of the child) and the birth order of the children with congenital heart disease were noted. The parental age and birth order of 100 consecutive normal Chinese children born in Singapore during the same period were similarly recorded.

To distinguish the separate effects of paternal age, maternal age, and birth order, which are usually well correlated with one another, the method of Smith, ${ }^{5}$ using multiple regression analysis, was used.

A computer programme was written specially for the Apple II microcomputer to compute all the required calculations.

The method and terminology of $\mathrm{Smith}^{5}$ was followed closely. The essence of this method is that, given the matrix of the coefficients of regression (for the controls),

$$
\boldsymbol{\beta}=\left[\begin{array}{lll}
\beta_{\mathrm{mm}} & \beta_{\mathrm{mf}} & \beta_{\mathrm{mb}} \\
\beta_{\mathrm{fm}} & \beta_{\mathrm{ff}} & \beta_{\mathrm{fb}} \\
\beta_{\mathrm{bm}} & \beta_{\mathrm{bf}} & \beta_{\mathrm{bb}}
\end{array}\right]
$$

(where $\beta_{\mathrm{mf}}$ is the coefficient of regression of mother's age on father's age and so on), it is possible to test the hypothesis 'that only the father's age has any appreciable real influence on the condition, the rises in the mother's age and birth rank being statistical consequences of this' (as well as similar hypotheses involving the mother's age and the birth order). ${ }^{5}$ The variance-covariance matrix is given by

$$
v=\left[\begin{array}{lll}
v_{\mathrm{mm}} & v_{\mathrm{mf}} & v_{\mathrm{mb}} \\
v_{\mathrm{fm}} & v_{\mathrm{ff}} & v_{\mathrm{fb}} \\
v_{\mathrm{bm}} & v_{\mathrm{bf}} & v_{\mathrm{bb}}
\end{array}\right]
$$


(where $v_{\mathrm{mm}}$ denotes the variance of $\mathrm{m}$, the maternal age, in the sample, $v_{\mathrm{mf}}$, the covariance of $\mathrm{m}$ and $\mathrm{f}$, and so on).

The expected rise in the mother's age (and similarly for the father's age and the birth order) is $\beta_{\mathrm{mf}} \Delta_{\mathrm{f}}$, where $\Delta_{\mathrm{m}}$ is the observed rise in the mother's age, and the difference between observed and expected is $\Delta_{m}-\beta_{m f} \Delta_{f}$. The error variance of $\Delta_{n}$ is $v_{\mathrm{mm}} / \mathrm{n}$, where $\mathrm{n}$ is the number of observations in the sample, the error variance of $\Delta_{\mathrm{f}}$ is $v_{\mathrm{ff}} / \mathrm{n}$, and their covariance is $v_{\mathrm{mf}} / \mathrm{n}$. Hence, the error variance of $\Delta_{\mathrm{m}}-\beta_{\mathrm{mf}} \Delta_{\mathrm{f}}$ is given by

$$
\left(\prime_{\mathrm{mm}}-2 \beta_{\mathrm{mf}}{ }^{\prime \prime m f}+\beta_{\mathrm{mf}}^{2}{ }^{\prime \prime f f}\right) / \mathrm{n} \text {. }
$$

Smith's method also allows estimation of the expected independent changes $\left(d_{m}, d_{f}, d_{b}\right)$ in the variables $m, f$, and $b$. The expected increase in the mean maternal age $m$ owing to $d_{m}, d_{f}, d_{b}$ is $d_{m}+\beta_{m f}$ $d_{f}+\beta_{m f} d_{b}$. By setting this equal to the observed increase $\triangle_{m}$, we have

$$
\mathrm{d}_{\mathrm{m}}+\beta_{\mathrm{mf}} \mathrm{d}_{\mathrm{f}}+\beta_{\mathrm{mb}} \mathrm{d}_{\mathrm{b}} \approx \Delta_{\mathrm{m}}
$$

In all, there are three linear equations for the three unknowns $d_{m}, d_{f}$, and $d_{b}$. which are written in matrix form $\beta d \approx \Delta$ where $d$ is the column vector with elements $\left[\mathrm{d}_{m}, \mathrm{~d}_{\mathrm{f}}, \mathrm{d}_{\mathrm{b}}\right]^{\mathrm{T}}$ and $\Delta$ similarly is given by $\left[\Delta_{m}, \Delta_{f}, \Delta_{b}\right]^{T}$. This has the solution $\mathbf{d} \approx \boldsymbol{\beta}^{-1} \Delta$. The error variance matrix is given by $\operatorname{var} d=\beta^{-1} v$ $\left(\beta^{-1}\right)^{\mathrm{T}} / \mathrm{n}$.

The values of $d_{m}, d_{f}$, and $d_{b}$ are compared with the size of their respective standard errors to determine whether there are independent paternal age, maternal age,'or birth order effects.

\section{Results}

The parental ages and birth order of the 100 Chinese children with congenital heart disease and the 100 controls are shown in table 1 and the correlation coefficients listed in table 2 . The birth order of the children with congenital heart disease was significantly higher than the controls $(p<0.01)$, but there was no significant difference in the paternal and maternal ages of the patients and controls $(p>0.05)$. As expected, the parental ages and birth order were

TABLE 1 Parental age and birth order in congenital

\begin{tabular}{|c|c|c|c|c|}
\hline & & $\begin{array}{l}\text { Father's } \\
\text { age }(y r)\end{array}$ & $\begin{array}{l}\text { Mother's } \\
\text { age (yr) }\end{array}$ & $\begin{array}{l}\text { Birth } \\
\text { order }\end{array}$ \\
\hline $\begin{array}{l}\text { Congenital heart } \\
\text { disease }(n=100)\end{array}$ & $\begin{array}{l}\text { Mean } \\
\text { SD } \\
\text { Mean } \\
\text { SD }\end{array}$ & $\begin{array}{r}31 \cdot 51 \\
6 \cdot 10 \\
30 \cdot 37 \\
4 \cdot 52\end{array}$ & $\begin{array}{r}27 \cdot 66 \\
5 \cdot 41 \\
26 \cdot 55 \\
3 \cdot 83\end{array}$ & $\begin{array}{l}2 \cdot 78 \\
2 \cdot 24 \\
2 \cdot 09 \\
1 \cdot 01\end{array}$ \\
\hline \multicolumn{2}{|c|}{$\begin{array}{l}\text { Observed rise in parental age } \\
\text { or birth order } \\
\text { Significance of difference }\end{array}$} & $\begin{array}{c}1 \cdot 14 \\
p>0.05\end{array}$ & $\begin{array}{c}1 \cdot 11 \\
p>0.05\end{array}$ & $\begin{array}{l}0.69 \\
p<0.01\end{array}$ \\
\hline
\end{tabular}
heart disease.
TABLE 2 Correlation coefficients.

\begin{tabular}{lll}
\hline & $\begin{array}{l}\text { Congenital } \\
\text { heart disease }\end{array}$ & Controls \\
\hline Father's age and mother's age & 0.7219 & 0.5809 \\
Father's age and birth order & 0.5612 & 0.4588 \\
Mother's age and birth order & 0.4789 & 0.4696 \\
\hline
\end{tabular}

all well correlated with one another for both groups of children, with correlation coefficients ranging from 0.46 to $0.72(\mathrm{p}<0.0001)$.

The matrix for the regression coefficients (controls) are shown below:

$$
\boldsymbol{\beta}=\left[\begin{array}{lll}
1.0000 & 0.4916 & 1.7871 \\
0.6863 & 1.0000 & 2.0628 \\
0.1234 & 0.1020 & 1.0000
\end{array}\right] .
$$

The variance-covariance matrix for the children with congenital heart disease is as follows:

$$
v=\left[\begin{array}{rrr}
29 \cdot 2368 & 23 \cdot 8014 & 5 \cdot 8032 \\
23 \cdot 8014 & 37 \cdot 1817 & 7 \cdot 6689 \\
5 \cdot 8032 & 7 \cdot 6689 & 5 \cdot 0218
\end{array}\right]
$$

The error variance matrix is given by

$$
\operatorname{var} \mathbf{d}=\left[\begin{array}{rrr}
0.4195 & -0.1029 & -0.0760 \\
-0.1029 & 0.4188 & -0.0451 \\
-0.0760 & -0.0451 & 0.0700
\end{array}\right] \text {. }
$$

The values of $d_{m}, d_{f}$, and $d_{b}$, their standard errors $尺$ and the significance of the parental age and birth order effects are shown in table 3. There was no significant paternal or maternal age effect $(p>0.05)$. but the birth order effect was significant $(p<0.01)$. The various types of congenital heart disease are shown in table 4.

TABLE 3 Significance of parental age and birth order effects.

\begin{tabular}{lll}
\hline Factor acting independently & $\begin{array}{l}\text { Standard } \\
\text { error }(S E)\end{array}$ & $p$ value \\
\hline Maternal age $-0.020(0.03 \times \mathrm{SE})$ & 0.648 & $\mathrm{p}>0.05$ \\
Paternal age-0.348 $(0.54 \times \mathrm{SE})$ & 0.647 & $\mathrm{p}>0.05$ \\
Birth order $0.730(2.75 \times \mathrm{SE})$ & 0.265 & $\mathrm{p}<0.01$ \\
\hline
\end{tabular}

TABLE 4 Types of congenital heart disease.

\begin{tabular}{lc}
\hline Diagnosis & Number \\
\hline Ventricular septal defect & 22 \\
Fallot's tetralogy & 19 \\
Pulmonary stenosis + ventricular or atrial septal defect & 11 \\
Persistent ductus arteriosus & 8 \\
Transposition of great vessels \pm other lesions & 8 \\
Endocardial cushion defect & 7 \\
Double outlet right ventricle & 6 \\
Pulmonary atresia \pm ventricular septal defect & 5 \\
Pulmonary valvular stenosis & 3 \\
Coarctation of aorta \pm other lesions & 3 \\
Others (including Ebstein's anomaly, aorto-pulmonary & \\
$\quad$ window, persistent truncus arteriosus, total & \\
anomalous pulmonary venous drainage, and cor & 8 \\
triatriatum) & 100 \\
Total & \\
\hline
\end{tabular}




\section{Discussion}

This is the first study, as far as we are aware, of the parental age and birth order effects in Chinese children with congenital heart disease. A moderate birth order effect is demonstrated.

Nora $^{6}$ and Nora et $a l^{7}$ demonstrated a multifactorial inheritance for congenital heart disease. They showed that the risk of recurrence of a congenital heart defect in another child in a family varies with the frequency the lesion is found in the general population and the type of lesion in the first affected child, the recurrence risk ranging from about 1 to $4 \%$. Applying Falconer's model ${ }^{8}$ for the estimation of heritability to their data, it can be shown that the heritability of various types of congenital heart disease is in the order of 50 to $80 \%$. This measure can give some indication of the relative importance of heredity and environment in the causation of the disease.

The presence of a birth order effect in congenital heart disease is indirect evidence of the presence of an environmental influence in the causation of the disease and is thus consistent with what is known about the multifactorial inheritance of congenital heart disease. While the exact mechanism of the birth order effect is at present unclear, this finding may nevertheless have practical applications. The increase in the incidence of congenital heart disease with the higher birth orders would suggest that family planning to reduce the size of families may possibly contribute towards the lowering of the incidence of congenital heart disease.

\section{References}

1 Emery AEH. Methodology in medical genetics. An introduction to statistical methods. Edinburgh, London, New York: Churchill Livingstone, 1976.

2 Jones KL, Smith DW, Harvey MAS, Hall BD, Quan L. Older paternal age and fresh gene mutation: data on additional disorders. J Pediatr 1975;86:84-8.

3 Carter CO. The inheritance of common congenital malformations. Prog Med Genet 1965;4:59-84.

4 Fedrick J. Anencephalus: variation with maternal age, parity, social class and region in England, Scotland and Wales. Ann Hum Genet 1970;34:31-8.

5 Smith CAB. Note on the estimation of parental age effects. Ann Hum Genet 1972;35:337-42.

- Nora JJ. Multifactorial inheritance hypothesis for the etiology of congenital heart disease. Circulation 1968 ;38 : 604.

7 Nora JJ, Vargo TA, Nora AH, et al. Dexamphetamine: a possible environmental trigger in cardiovascular malformations. Lancet $1970 ; \mathbf{i}: 1290$.

8 Falconer DS. The inheritance of liability to certain diseases, estimated from the incidence among relatives. Ann Hum Genet 1965;29:51-76.

Requests for reprints to Professor John Tay, University Department of Paediatrics, Singapore General Hospital, Outram Road, Singapore 0316. 